\title{
DOES HAPPINESS DIFFER ACROSS CULTURES?
}

Ruut Veenhoven, Erasmus University Rotterdam, Netherlands and North-West University, South Africa

H. Selin, G. Davey (eds.). Happiness Across Cultures, Views of happiness and quality of life in non-western cultures, DOI 10.1007/978-94-007-2700-7_30, Springer Dordrecht. 2012, pp 451-472 Book series Science across cultures: The history of non-western science vol. 6, ISBN 978-94-007-2699-4

\section{INTRODUCTION}

This book deals with a classic question in the study of happiness: Is happiness similar for all humans, or is it something that varies across cultures? In the universalistic view, happiness is comparable to pain. All humans know what pain is, will experience pain when touching a hot stove, and tend to avoid pain. In the cultural view, happiness is more comparable to beauty, the idea of which varies across time and culture.

This discussion links up with wider issues, among which is the longstanding debate about the merits of utilitarian moral philosophy first proposed by Jeremy Bentham in 1789. Its 'greatest happiness principle' assumes that happiness is something universal. If happiness is different in different cultures, it cannot serve for the comparative evaluation of cultures. If culturally variable, the definition of happiness can also change over time, and is then not a strong criterion for public choice within cultures. These arguments have been presented repeatedly in the literature, but few conclusions can be drawn from the discussions because of a lack of empirical evidence for either position.

In this chapter, I inspect what present day knowledge about happiness can tell us about this old controversy. Has a decade of empirical research made us any wiser on this matter, or are we still as much in the dark as the 19th Century armchair philosophers who criticized utilitarianism on this ground?

An earlier version of this paper entitled "How Universal is Happiness?" was published as Chapter 11 in Ed Diener, John F. Helliwell, and Daniel Kahneman (Eds.). (2010). International differences in wellbeing (pp. 328-350). New York: Oxford University Press. 


\subsection{Concept of Happiness}

The first step in my discussion is to define happiness, since some of the things denoted with this word can be less universal than others. I use the word 'happiness' for a subjective state of mind, which I define as the overall appreciation of one's life as-a-whole. I have elaborated this definition in earlier publications (Veenhoven 1984a, chapter 2, 2000). This definition fits Bentham's classic notion of happiness as 'the sum of pleasures and pains'. Happiness in this sense is synonymous with terms such as 'life satisfaction' and 'subjective wellbeing'.

\subsection{Questions}

The question whether happiness differs across cultures is too broad to answer, since there are different facets of happiness that might vary across cultures. Therefore I will break down the main question into the following sub-questions:

(1) Do all humans appraise how much they like their lives?

(2) Do they appraise life on the same grounds?

(3) Are the conditions for happiness similar for all humans?

(4) Are the consequences of happiness similar around the globe?

(5) Do all humans seek happiness?

(6) Do humans seek happiness in similar ways?

(7) Are humans equally happy in all cultures?

Since the focus of this chapter is on cultural variation in the nature of happiness, I do not deal with the cross-cultural measurement of happiness. Cultural measurement bias may distort the data on which my discussion builds in several ways, but the literature suggests that the degree of distortion is not alarming (Diener \& Oishi 2004; Veenhoven 2008a).

\subsection{Data Source}

Most of the empirical data used in this paper are taken from the World Database of Happiness (Veenhoven 2011a). This is a 'findings archive' that involves standardized descriptions of empirical research findings on happiness as defined above. The archive started as a 'Data book of Happiness' (Veenhoven 1984b) and is now on a website (Veenhoven 201 la). To date it involves some 18,000 research findings. The aim of this collection is to facilitate research synthesis in this field (Veenhoven 2009a).

Findings on degree of happiness are gathered in the collection of Distributional Findings, which involves subsections on Happiness in Nations (Veenhoven 2011b) and on Happiness in Publics (Veenhoven 2011c). Each of these findings is presented on a standard page with information about (1) population and sampling.

(2) the measure of happiness used, (3) the observed frequency distribution of happiness and the summary statistics mean and standard deviation, each with a $95 \%$ confidence interval. Findings on things that go together with happiness are stored in the collection of Correlational Findings (Veenhoven 2011d). Finding pages in this collection involve additional information about: (4) the measurement of co-variates and (5) the observed statistical association with happiness. All finding pages also involve a reference to the research report from which the information is taken, and often a link to the full text. 
Finding pages are ordered by subject in 'Finding Reports'. In this text I will refer to these reports. Citing all the research findings separately is not workable, because there are too many. Finding reports are mentioned in endnotes.

When evaluating our lives, we draw on two sources of information: how well we feel generally and how well life-as-it-is meets up with our standards of how-life- shouldbe. This theory is summarized in Scheme 1 and discussed in more detail in Veenhoven (2009b). Both appraisals seem to be universal, and so is the tendency to merge this information in an overall evaluation of life.

\subsection{Affective Appraisal}

Like other higher animals, humans are hard wired for emotional experience. Basic emotions appear to be universal and are recognized in the facial expressions of other people all over the world (Ekman 1970). Using brain imaging, it is possible to observe some of the neural processes that relate to emotions (e.g. Davidson 2004), and these do not seem to differ across cultures either. There is some cultural variation in recognition of 'fear', 'anger' and 'disgust' in facial expressions (Russell 1994). Still, the pattern is largely universal and recognition of 'happy' emotion stands out as the most universal.

Emotional experience involves positive and negative affects and the balance of these is reflected in the hedonic tone of 'mood'. Though mood is something we are aware of, it is mostly not in the foreground of our consciousness. Still it is assessable, and we can estimate how well we feel most of the time. Babies are not yet able to do such reflection, but they experience happy or unhappy moods. Although they cannot say how they typically feel, their mood level can be assessed using behavioral indications, which illustrates that one can feel happy without necessarily having a concept of happiness in mind.

Adult humans know how well they feel most of the time, and appear to be able and willing to answer questions about that, such as in the context of happiness surveys. When asked how well they usually feel, people answer instantly, and nonresponse rates are small. Self-ratings of average hedonic level do not differ much from the balance scores scientists compute from responses to multiple questions about specific affects, ${ }^{1}$ and do not differ substantially from ratings based on experience sampling $^{2}$ or from ratings by intimates. ${ }^{3}$

\subsection{Cognitive Appraisal}

Unlike their fellow animals, humans can develop ideas of what they want from life and then compare the extent to which their lives meet these aspirations. This ability is not present from birth, but develops on the road to adulthood. There is no doubt that all adults have wants (even ascetics who denounce all wants still have the want to denounce wants), and there is also no doubt that most adults have an idea of how well their wants are being met, at least important wants. Wants are often not very specific, and few people have clear priorities in mind, but, nevertheless, most people have no problem estimating their success in getting what they want from life. 
Several surveys of happiness have included questions about what one wants from life and the degree to which these wants are being met. For example, a common question is: "So far, I have gotten the important things I want in life" (item in Diener's Satisfaction With Life Scale, which is a popular scale in happiness studies (Diener, Emmons, Larsen, \& Griffin 1985)). The responses to such questions are also prompt, and the percentage of respondents answering with the 'Don't know' option is very low. So apparently this question links up with something people have in mind. Even if people have no overall judgment of success ready in mind, they typically think of one when asked. This appears in the practice of focused interviews, particularly life-review interviews. However, as in the case of hedonic level, it is not required that people have an overall judgment in mind, as an external observer can estimate someone's overall contentment based on that person's reported success in meeting their specific wants.

\subsection{Overall Appraisal}

Human cognition enables us to make comprehensive judgments of the things we like. This ability is quite functional in the human behavioral repertoire, which depends on choice rather than instinct.

In this context, it is no surprise that people have no difficulties reporting the extent to which they like their lives-as-a-whole. Responses to questions on overall happiness are also prompt; if not, happiness would not be such a common item in survey research. The non-response level to questions on happiness is low again. Less than $1 \%$ uses the 'Don't know' option, ${ }^{4}$ and few people skip the question. Analysis of non-response to the questions on happiness and life-satisfaction in the World Values Survey shows some variation across cultures. The percentage of 'don't know' responses is slightly higher in nations where unhappiness prevails $(\mathrm{r}=+0.10)$ and also higher in collectivistic cultures $(\mathrm{r}=+0.21)$. Still these are variations on an otherwise universal pattern. See Scheme 2. Non-response is much higher on questions about other issues such as income and political preference. Questions on life satisfaction are also easily answered in non-modern societies, such as the Inughuit, the Amish and the Maasai (Biswas-Diener, Diener, \& Vitters0 2005).

\section{DO HUMANS APPRAISE LIFE ON THE SAME GROUNDS?}

In answering question 1 above, I argued that all humans appraise life both affectively and cognitively. In answering question 2 below I will consider possible cultural differences in these two appraisals of life.

\subsection{Hedonic Level Depends on Gratification of Universal Needs}

Why do we experience pleasure and pain? The biological function is, evidently, to signal that things are good or bad for us. Evolution has programmed us this way.

What then is the function of mood? It is clearly not to signal specific benefit or danger; unlike pleasure and pain, moods are typically not related to specific stimuli and certainly not average mood levels over longer periods of time. Mood level seems to function as a meta-signal to indicate how well we are doing on the whole. Feeling good means that all lights are on green, and that we can go ahead, while feeling bad 
means that there is something wrong and that we should check what that is. This affective signal mechanism seems to exist in all higher animals, and its neural basis is found in the eldest parts of the human brain.

What then is 'doing well'? I assume, but cannot demonstrate, that this is meeting innate needs. 'Needs' are requirements for functioning the gratification of which is safeguarded with affective signals. This is pretty evident in the case of 'deficiency needs' such as hunger, but seems also to apply to 'growth needs' such as curiosity, as distinguished in Maslow's (1970) theory of human motivation.

In this view, happiness roots in the gratification of basic needs that are part of human nature. In that respect, happiness draws on universal grounds. I have discussed this 'need theory' of happiness in more detail elsewhere (Veenhoven 1991, 2009b).

Contentment Depends on Meeting Culturally Variable Wants

Why do we have wants? Wants are ways to gratify needs. In lower animals, needs are met by means of instinctive behaviors. The human strategy is more flexible, and allows need gratification though planned behavior: 'Wants' are part of that planning.

Why do we want what we want? Part of the answer is that we tend to adopt current standards of the good life; for example, the standard of what material level of living is fair. These standards vary across time and culture; today we want more material comfort than our great grandparents could have dreamt of. In this view, happiness is grounded in social standards, and in this respect happiness is culturally relative. For example, the material standard of living is set higher in American business circles than in Tibetan monasteries. For a relevant statement see Chambers (1999) who argues that current standards of psychological wellbeing root in the values of individualized western society.

\subsection{Experience Dominates in Overall Evaluation of Life}

In this line of reasoning, the universality of happiness boils down to the question of which of these two ways of appraising life is the most important. I have considered this question in earlier publications (Veenhoven 1991, 2009b) and concluded that affective experience dominates the overall evaluation of life. Below I will summarize the main arguments and present more evidence.

\section{Theoretical Plausibility}

From an evolutionary perspective, it is not plausible that cognitive comparison dominates the overall evaluation of life. Cognition developed much later, and serves as an addition to affective appraisal rather than as a substitute. Reason helps to explain why we feel good or bad and allows detection of false affective signals, although it is difficult to ignore these, as depressives know. Affective appraisal tends to precede cognitive decision (Zajonc 1984), and without affective appraisal we cannot come to a decision, as cases of brain damage demonstrate (Damasio 1994). In this perspective it is also unlikely that humans orient on variable cultural standards in the first place, rather than on needs that root in biological evolution.

Rayo and Becker (2007) have a different view and argue that we are hardwired to compare and prefer the best, since this is an evolutionary advantage. Their argument is appealing. Still, more is not always better and can even be detrimental. The tendency to compare can also be explained on the basis of innate needs that are not exclusively human, such as the need for social status and the need 
to use and develop one's potentials. I do accept that we tend to see things in a comparative perspective, but see that rather as a consequence of cognition than as a need in itself. The distinction between consequences of human consciousness and innate needs is further discussed in the response to question 5.

The limited role of cognitive comparison is also illustrated by the fact that it does not exist in young children, who as yet have no idea of what they want from life. Still it is clear that children can be happy or unhappy, and there is typically no great change in happiness when they develop wants.

\section{Empirical Indications}

Since we cannot (yet) look into people's heads, there is no direct empirical evidence of the relative strength of both ways of appraising life. Even so, there are several indirect indications.

Overall Happiness More Correlated to Affect Than to Contentment If affective experience dominates the overall appraisal of life, this should appear in sizable correlations with overall happiness and more sizable correlations than with contentment. Unfortunately there are no studies involving measures of all three of these variants of happiness, so we must do with studies that correlated either overall happiness with affect or overall happiness with contentment. The findings of such studies are stored in the World Database of Happiness, which distinguishes measures of overall happiness (coded ' $O$ '), measures of affect level (coded 'A') and measures of contentment (coded 'C') (Veenhoven 2011e).

Eight studies link self-ratings of overall happiness and average affect. Observed correlations range between +0.30 and +0.77 , with an average of $+0.70 .^{5}$ Another 13 studies relate responses to global questions on overall happiness and contentment and find an average correlation of $+0.46 .{ }^{6}$ Likewise, the average correlation between overall happiness and affect balance in 70 studies is about $+0.50 .^{7}$ Not surprisingly, the correlation between hedonic level and contentment is weaker, the average in 3 studies is $+0.40 .^{8}$ An even lower correlation of about +0.20 was observed in the recent Gallup World Poll, which asked both how one had felt yesterday and how one's life rates on a scale ranging from 'best possible' to 'worst possible' (Harter \& Arora 2010).

Happy with Unfulfilled Aspirations If happiness depends on meeting wants, people must be unhappy when they have unfulfilled aspirations, and increasingly unhappy the more unfulfilled aspirations they have. Yet people with unfulfilled aspirations appear to be happier than people without, and more so when they have more unfulfilled aspirations (Wessman 1956, p. 210. Wessman wrongly interpreted table 44 as showing that unfulfilled aspirations go with unhappiness). This finding fits better with the theory that we have an innate need to use our potentials, since unfulfilled aspirations provide an aim to achieve.

Happy in Spite of Value-Reality Gap If contentment drives happiness in the first place, it can be expected that people are happier in nations where the values endorsed are perceived to be met (in contrast to nations where a gap between value and reality is perceived to exist). This is not always the case; for instance, it is not so with 'gender equality' and 'human orientation' as measured in the Globe study in 62 
societies (House, Hanges, Javadin, Dorfman, \& Gupta 2004). Average happiness is higher in nations where the widest gaps between ideal and reality are perceived to exist on these issues, probably because this marks a more human-friendly social climate.

Happiness Drives Contentment The right arrow in Scheme 3 denotes a 'bottom-up' effect of contentment on overall happiness. Above I have interpreted the observed correlations in this way. Yet causality can also be 'top-down', with overall happiness affecting the perception of the gap between what one wants and what one has. Analysis of a follow-up study has shown that causality typically works this way. In this study, discrepancies (gaps) were assessed between how respondents rated their present life on a 20-step scale and ratings of what they wanted from life (expectations, aspirations, entitlements) on the same ladder scale. Comparison over time showed a significant top-down effect, that is, earlier happiness predicts smaller gaps later. No bottom up effect was found; earlier perception of gaps did not predict later happiness (Headey \& Veenhoven 1989, p. 117). So it seems that contentment is largely driven by happiness: If we feel good, we infer that we have most of the things we want, and if we feel bad, we start looking for what we might be missing.

Though affect seems to dominate the overall appraisal of life, its influence varies across cultures. Correlations between overall happiness and affect balance tend to be stronger in individualistic nations, such as the USA, than in collectivistic ones, such as Japan (Suh, Diener, Oishi, \& Triandis 1998). Likewise, the relative weight of positive and negative affect differs somewhat across cultures. Negative affect is more strongly correlated to overall happiness in individualistic nations than in collectivistic ones, while positive affect correlates more with overall happiness in nations where self-expression values are endorsed than in nations where the focus is more on survival (Kuppens, Realo, \& Diener 2008).

\section{Question 3:}

\section{ARE CONDITIONS FOR HAPPINESS SIMILAR ACROSS CULTURES?}

Do humans need the same conditions to be happy? Or can some people be happy in conditions that render other people unhappy? Below I will consider this question on two levels: the macro level of nations and micro level of individuals within nations.

\subsection{Uniformity in Societal Requirements for Happiness}

Average happiness differs markedly across nations: the highest average on a 0 to 10 scale is currently observed in Denmark (8.2) and the lowest in Zimbabwe (3.2). ${ }^{9}$ There is a clear pattern in these differences. People live happier in the most modem nations, in particular those characterized by economic development, freedom, rule of law and good governance. The societal characteristics set out in Scheme 4 explain no less than $75 \%$ of the national differences in average happiness. Similar results are obtained when average happiness is measured using an Affect Balance Scale instead of a single direct question on satisfaction with life-as-a-whole (Variable in data file 'States of Nations' (Veenhoven 2011f): 'HappinessYesterdaysAffect3_2006'). Societal progress in these matters is likely to have fostered the recent rise of happiness in modern nations (Inglehart, Foa, Peterson, \& Wetzel 2008). 
Interestingly, the societal conditions that make people happy are not always the conditions they value. For instance, average happiness is markedly lower in nations where women are discriminated against (Chin-HonFoei 2007), but this practice is widely approved in most of these countries. Likewise, corruption brings down happiness even in societies where favouritism is seen as a moral obligation.

\subsection{Uniformity in Conditions for Happiness Within Nations}

There is also much difference in individual happiness within nations. For example, in a happy country like Denmark, $5 \%$ of the people still rate themselves 5 or lower on the $0-10$ response scale; and in an unhappy country like Zimbabwe, some $13 \%$ score 8 or higher. Are the reasons for high and low scores similar across nations? Below I consider some conditions for which cross-national data are available.

\section{Freedom}

Not only is average happiness higher in free countries, but within countries individuals are also happier when they have more control over their lives. This appears, among other things, in strong correlations between personal happiness and perceived freedom and control all over the world. ${ }^{10}$

\section{Social Rank}

People are typically happier on the upper steps of the social ladder than at the bottom. This appears in findings on relative income position, ${ }^{11}$ occupational prestige, ${ }^{12}$ subjective class identification ${ }^{13}$ and indexes of socio-economic status. ${ }^{14}$ The differences tend to be bigger at the lower end of the hierarchy. Though the correlations with happiness differ in size, they are positive all over the world. This finding fits the view that we have an innate need for social respect. Like other group animals, we avoid the lowest rungs of the social ladder.

\section{Marriage}

Adults are typically happier when living with a spouse than when single. The difference is around half a point on scale $0-10$, and is largely independent of income, gender and age. Again the size of the difference varies somewhat across time and nations, but the pattern is clearly universal. ${ }^{15}$ This finding fits the view that we are pair-animals who need a mate.

\section{Personality}

Cross national research on the relationship between happiness and personality is limited as yet, but the available data across a variety of nations suggest that extroverted people tend to be happier (Lucas, Diener, Grob, Suh, \& Shao 2000). Schimmack, Radharkrishan, Oishi, Dzokoto, and Ahadi (2002) found that the link between extraversion and hedonic level of affect is more universal than the link between extraversion and overall happiness and suggest that the influence of personality on the emotional component of happiness is pan-cultural, whereas the influence of personality on the cognitive component of happiness is more moderated by culture. Once more, there is a difference in the size of the effects. For instance, the effect of self-esteem appears to be stronger in individualistic cultures than in collec- tivistic cultures (Oishi, Diener, Lucas, \& Suh 1999). Still, the direction tends to be the same everywhere; people with high self-esteem tend to be happier. 
This is not to say that all conditions for happiness are universal. One notable exception is education. Although there is a correlation between average happiness and level of education in countries, the most highly educated individuals are not always happier. Correlations between happiness and education vary between -0.08 to +0.27 . $^{16}$

ARE THE CONSEQUENCES OF HAPPINESS SIMILAR ACROSS CULTURES?

Although a great deal of research into happiness has focused on its determinants, there is also a strand of investigation into the consequences of enjoying life or not (Veenhoven 1989; Lyubomirsky, Diener, \& King 2005). Fredrickson (2004) has summarized much of the findings in the 'broaden and build theory' of positive affect. Although most of this research has been done in Western nations, the observed effects are also likely to exist in other parts of the world.

\subsection{Happiness Fosters Functioning}

Happiness appears to encourage engagement, while unhappiness tends to instigate withdrawal. This appears as greater engagement in activity at work ${ }^{17}$ and in leisure. ${ }^{18}$ The energizing effect of happiness manifests also in social behavior. Happiness predicts the formation of friendships, ${ }^{19}$ marriage, ${ }^{20}$ and participation in voluntary organizations. ${ }^{21}$ There is also experimental evidence of happy moods broadening perception. When we are in a good mood, we tend to be more curious and imaginative and this results in greater creativity (Isen, Doubman, \& Nowiki 1998). All this is in agreement with the above-mentioned theory that happiness works as a 'go signal', and that this effect seems to exist also in other higher animals. If so, the effect is likely to be universal.

\subsection{Happiness Lengthens Life}

Another illustrative finding is that happiness fosters physical health, ${ }^{22}$ and that happiness lengthens life considerably ${ }^{23}$ One of the likely mechanisms seems to be that happiness encourages the full functioning of mind and body, which keeps us in shape. Also likely is that unhappiness triggers the fight-flight response, since it signals that there is something wrong, which makes an organism economize on other physiological functions, including the immune response. In this line, Cohen, Doyle, Skomer, Fireman, Gwaltney, and Newson (1995) demonstrated experimentally that unhappiness makes people more susceptible to catching a common cold. The above are essentially biological reactions that are unlikely to differ much across cultures. Possibly there are effects of happiness that do differ across cultures, but for the time being it is the universality that is striking.

\section{DO ALL HUMANS SEEK HAPPINESS?}

It seems obvious that most humans prefer a happy life rather than an unhappy one. 
But this does not mean that happiness is the main driver in human motivation or that happiness is valued universally.

\subsection{Happiness is a Universal Human Striving, Though Not Innate}

In the first lines of his famous Principles of Morals and Legislation, Jeremy Bentham (1789) stated that human behavior is governed by the pursuit of pleasure and the avoidance of pain. There is much truth in this theory of motivation, yet happiness is not the only driver of human behavior, at least not happiness in the sense of overall life satisfaction.

Like other mammals, we are driven by different needs, such as hunger, sex, love and curiosity, which have developed through evolution. All these needs are linked to hedonic signals, but their gratification is not only sought for the sake of pleasure. For instance, the need for sex cannot be substituted by the aesthetic pleasure of reading poetry. Pleasure is a main driver of human behaviour, but it is not quite the same as life satisfaction. Short-term pleasures can be at the cost of long-term happiness, and in such cases humans do not always look to the long term.

Like our fellow animals, humans are driven by primary motives, but our consciousness also gives rise to secondary motives, such as figuring out who we are and seeking answers to questions about the meaning of life. Wentholt (1980) calls these 'universal strivings', which he distinguishes from 'organic needs'. The pursuit of long-term happiness is one of these universal strivings. Though not innate as such, it is an inclination that develops in most humans as a result of their consciousness. While this inclination manifests in all cultures, it does not necessarily appear in all individuals. For instance, happiness is typically not a priority for people trying to survive, and some forsake happiness for ideological reasons.

\subsection{Happiness Is Valued in Most Societies, Though Possibly Not in All}

Happiness seems to be positively valued in all nations. This is at least suggested by a study of university students in 47 nations in the 1990s (Diener \& Oishi 2004). The students were asked to rate the importance of several values, such as happiness, wealth, health and love. Happiness ranked highest, with an average of 8 on a scale of 1 to 9 . Ratings ranged between 8.7 and 7.3, and there is thus no country in this study where happiness is deemed unimportant. No such case has appeared in other studies either. $^{24}$

This is not to say that happiness has always been prized in all human cultures. Though all humans have a natural inclination to pursue happiness, cultures can go against that inclination, just as some cultures go against the natural drive for sex. Which cultures denounce happiness? Unfortunately cultural anthropology cannot tell us, since this discipline has, until recently, turned a blind eye to happiness (Thin 2008). Even so, there are at least indications that past societies tended to glorify suffering rather than happiness. This appears for instance in the history of philosophical thought. Happiness was a common theme in the prosperous Antique city societies, but disappeared in the dark Middle Ages when the view dominated that men had been expelled from paradise and that happiness was possible only in afterlife. The idea of happiness in earthly life popped up again in the 17th century, together with a rise in quality of life of the new middle class in Europe.

One can think of reasons why cultures come to depreciate happiness. When life is miserable, it may be comforting to believe that happiness is no good after all; and 
renouncing happiness may be functional for engaging people in common causes such as war. Next to such macro-societal functions, internal factors can be involved, such as cultural distinction between groups in a society. This seems to have been one of the reasons for the sexual abstention of religious people during the Middle Ages. The campaign against happiness of some present-day philosophers (Bruckner 2000; Wilson 2008) could perhaps be placed in a similar vein as intellectual distinction. DO HUMANS SEEK HAPPINESS IN A SIMILAR WAY?

This question is easier put than answered, since behavior is typically guided by multiple motives that cannot be studied easily. Clues can be gleaned by looking at beliefs about conditions for happiness. Do universal themes dominate these beliefs or do these lay theories of happiness tend to be culture specific? This question can be answered in principle, but a shortage of data sets limits.

\subsection{Variation in Philosophical Views Raises More Questions Than Answers}

Can we answer this question on the basis of what prominent thinkers have said on this subject in different times and cultures? There is a large philosophical literature about ways to lead a happy life, ${ }^{25}$ and reviews of this literature, show wide differences. Yet even if philosophers differ so much, public opinion need not be equally diverse. Philosophers often seek differences from common opinions. Moreover, philosophers often use the term happiness in a broader sense than defined here, and typically write about how we should seek happiness rather than how we actually $d o$. So, to answer this question, perhaps it is better to look at survey research into beliefs about happiness.

\subsection{Survey Research Shows Much Similarity}

As yet there is more comparative research on degree of happiness around the world than on beliefs about conditions for happiness. The available research on presumed conditions for happiness is limited to present-day nation states. These data suggest that there is quite some similarity across nations.

Most of the available research findings are about perceived sources of one's own happiness. $^{26}$ The bulk concerns Western people, who tend to believe that happiness depends on health and good relations in the first place, and less so on material affluence and social prestige.

Only a few studies have compared happiness across cultures. Chiasson and Dube (1997) found striking similarities in North America and Latin American countries. Likewise, Lee, Park, Uhleman, and Patsula (1999) found that students in Canada and Korea employed essentially the same ordered set of perceived sources for happiness, in spite of considerable difference in average level of happiness. A recent Gallup World Survey (Spogárd 2005) found that a happy family life and good health are ranked high all over the world. See Scheme 5.

Belief about conditions for happiness was addressed indirectly in Cantril's (1965) landmark study on 'The pattern of human concerns' in 16 nations in the early 1960s. This study involved open-ended questions about what constitutes the 'best possible life' and the 'worst possible life'. Analyses of the responses showed much 
similarity, as the same themes popped up in all countries, though not equally frequent everywhere (pp. 162-167). The observed differences appeared to correspond more with stage of societal development than with ideology (p. 302). Cantril explained these observations in terms of need theory (Chapter XVI).

Studies by Tsai et al. (2006) address differences in both ideal and actual affect across cultures, and suggest that culture influences ideal affect more than actual affect, although their findings show much similarity in ideal affect, and similar high ratings for the desirability of happiness.

\section{Question 7:}

\section{ARE HUMANS ABOUT EQUALLY HAPPY IN ALL CULTURES?}

The last question is about degree of happiness. Are humans about equally happy in all cultures, or do they live happier in some cultures than in others?

Some variants of the comparison theory of happiness imply that humans are about equally happy everywhere. If happiness depends on comparison with compatriots, the average level will be about neutral in all societies. If happiness depends on comparison with earlier experiences over one's lifetime, the average will tend to neutral as well. Yet other variants of comparison theory imply that happiness can differ across cultures. If happiness depends on meeting local standards of the good life, it can be high in cultures where these standards can be easily met and low where the meeting of these standards is out of reach of most people. These views are discussed in more detail in Veenhoven (1991, 1995).

Need theory also implies that the level of happiness can differ across cultures. If happiness depends on the degree to which human needs are met, average happiness will be higher in societies that fit human nature better than others. From a functional point of view it is unlikely that we are equally happy, irrespective of conditions. At best, evolution has resulted in a tendency to feel happy once conditions are tolerable. The data are quite clear on this matter. There are wide differences in average happiness across nations. See Scheme 6. Average happiness ${ }^{27}$ is 8.3 in Denmark and only 3.0 in Zimbabwe. Average happiness is above neutral in the present day world. ${ }^{28}$ As we have seen in Scheme 4, most of these differences can be explained by nation characteristics such as wealth, freedom and security, which are part of modernity.

Average happiness does not only differ among contemporary cultures, but also varies over time. The level of happiness has risen in most nations over the last 30 years, but declined in some (Veenhoven \& Hagerty 2006; Inglehart et al. 2008). Average happiness fell dramatically in Russia and China following the great social changes that took place since the 1980s (Brockmann et al. 2009). Though people live happier in modem society, the change to modernity tends to reduce happiness temporarily.

There are also indications that average happiness has varied considerably over longterm human history. Our forefathers seem to have been fairly happy when living as hunter-gatherers, but less so in the agrarian phase of societal evolution. The industrial revolution brought not only more material comfort, but also an unprecedented rise in happy life years (Veenhoven 2010). 
The available data suggest that all humans tend to appraise how much they like life. In appraising life, humans draw on how well we feel in the first place, which in turn draws on how well innate needs are met. The overall appraisal of life draws less on cognitive comparison with cultural standards of the good life. Consequently, conditions for happiness appear to be quite similar across the world. The consequences of enjoying life are also largely universal. There is more cultural variation in the valuation of happiness and in beliefs about conditions for happiness. The greatest variation is to be found in how happy people are. 
Scheme 1

Concepts of happiness: Overall happiness and components

\begin{tabular}{lll} 
global assessment & $\begin{array}{l}\text { OVERALL HAPPINESS } \\
\text { Satisfaction with one's life-as-whole }\end{array}$ \\
sub-totals: & $\begin{array}{l}\text { Hedonic level of affect } \\
\text { Balance of pleasant and } \\
\text { unpleasant affect }\end{array}$ & $\begin{array}{l}\text { Contentment } \\
\text { Perceived realization } \\
\text { of wants }\end{array}$ \\
information basis & Affective experience & Cognitive comparison \\
\hline
\end{tabular}

Source: Veenhoven (1984a) 
Scheme 2

'Don't Know' response to survey questions about happiness

\begin{tabular}{ll} 
USA & $0.19 \%$ \\
Zimbabwe & $0.26 \%$ \\
China & $0.49 \%$ \\
France & $0.65 \%$ \\
Russia & $1.42 \%$ \\
India & $2.69 \%$ \\
Average in 78 nations & $\mathbf{0 . 7 5 \%}$ \\
\hline
\end{tabular}

Source: World Values Surveys (2010), life-satisfaction item, average waves 1 to 4 


\section{Scheme 3}

\section{Theories of happiness: significance of two causal path}

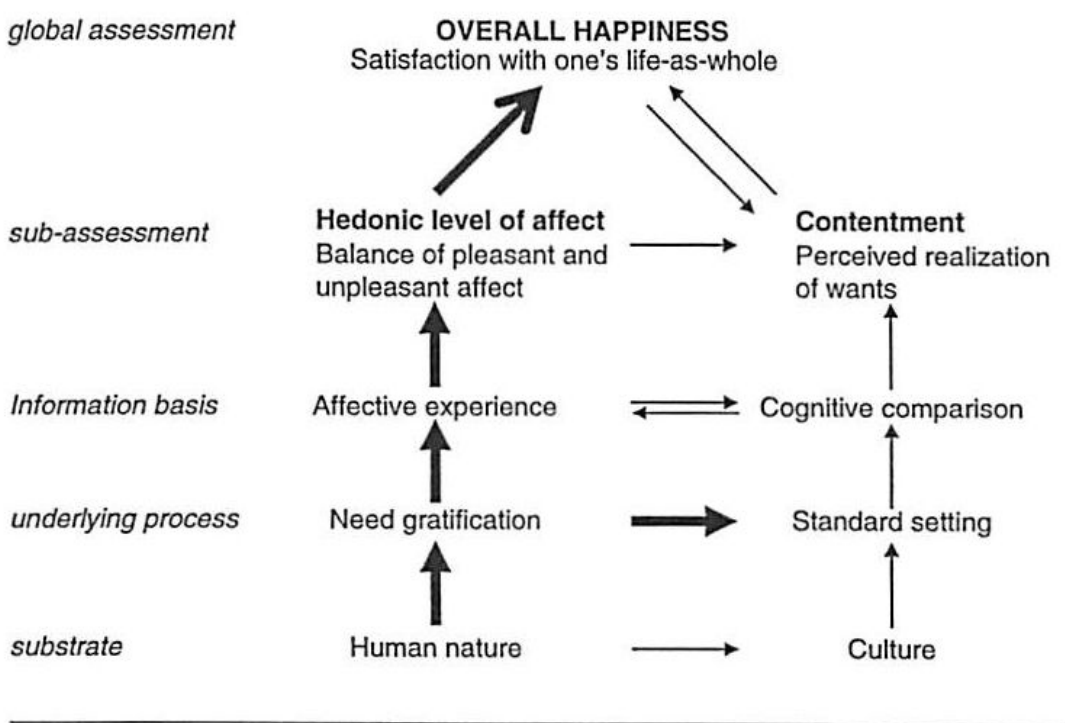

Source: Veenhoven (2009b) 


\section{Scheme 4}

\section{Average happiness in nations by societal characteristics}

\begin{tabular}{lll}
\hline & Zero order & wealth controlled \\
\hline Wealth & & \\
$\quad$ - Income p/c & +0.79 & - \\
Freedom & & \\
$\quad$ - Economic freedom & +0.62 & +0.11 \\
$\quad$ - Political freedom & +0.50 & +0.07 \\
Peace & +0.39 & +0.15 \\
Justice & & \\
$\quad$ - Corruption & -0.77 & -0.14 \\
$\quad$ - Rule of law & +0.70 & +0.06 \\
Equality & & \\
$\quad$ - Income equality & +0.27 & -0.33 \\
$\quad$ - Gender equality & +0.67 & +0.19 \\
Education & & \\
$\quad$ - School enrolment & +0.57 & +0.12 \\
$\quad$ - Intelligence & +0.63 & +0.21
\end{tabular}

Source: World Database of Happiness, data file States of Nations ${ }^{3}$

a The data file 'States of Nations' (Veenhoven 2011f) is available on request.

The variables used here are: IIappinessBWLS_2006, RGDP_2000_2004, FreeEconIndex2_2002,

DemocracyIndex2_2004, Peacelndex_2007, Corruption3_2006, RuleLaw_2006, IncomeInequality 1_2005, GenderEqualIndex 2 2005, EduEnrolḠross_2000_04, IQ_ 2006 


\section{Scheme 5}

Perceived sources of happiness

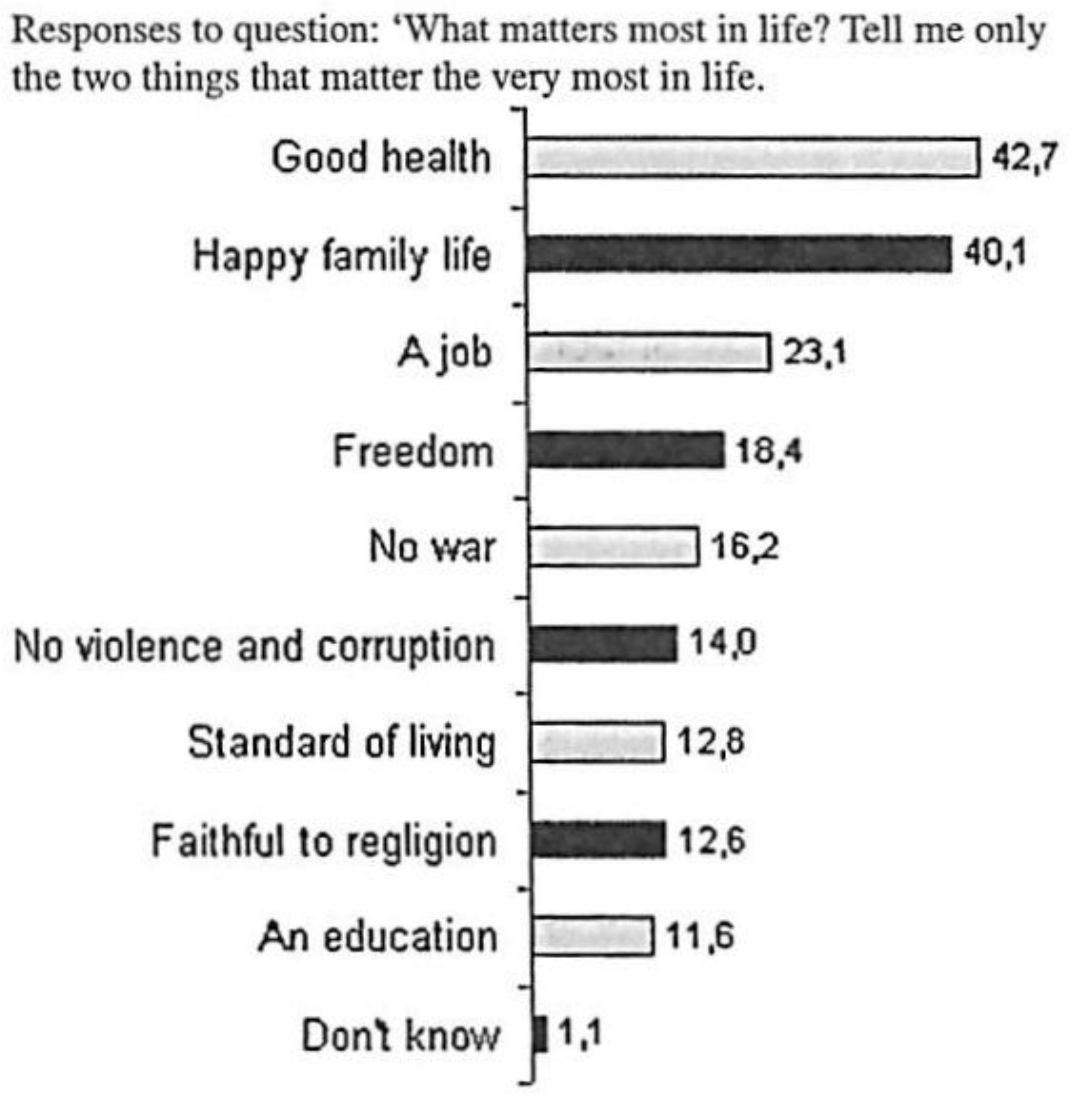

Source: Gallup Millennium World Survey (Spogárd 2005 
Scheme 6

Happiness in nations around 2005, averages on scale 0-10

Denmark

Sweden

USA

Germany

France

6.5

Philippines

6.4

Japan

6.2

Turkey

5.2

Russia

4.4

Zimbabwe

3.3

Average in 86 nations

6.5

Source: World Database of Happiness, Happiness in Nations (Veenhoven 2011b) 


\section{NOTES}

1 World Database of Happiness, Correlational Findings (Veenhoven 2011d), subject section 'Current Happiness' (H6.2.2.2), 1 study that observed a correlation of +0.56 .

2 World Database of Happiness, Correlational Findings (Veenhoven 2011d), subject section 'Current Happiness' (H6.2.2.3), 1 study.

3 World Database of Happiness, Correlational Findings (Veenhoven 2011d), subject section 'Reputation of Happiness' (H8.2), 4 studies which observed correlations between +0.43 and +0.64 .

4 World Database of Happiness, States of Nations (Veenhoven 2011f). Variable Happiness, DKLS_1980_2000. Average \% 'don't know' in 76 nations 0.75 , range, 0.4 to 4.5 .

5 This analysis involved 8 studies, the results of which are summarized in the World database of Happiness, Correlational Findings (Veenhoven 2011d), section H6.1.2 'Current happiness: Overall happiness by Hedonic level of Affect'. The analysis was limited to studies among general population samples using comparable single direct questions on overall happiness (type O-HL, O-SL, O-DT, OQOL) and Affect (type A-AOL).

6 This analysis involved 7 studies, the results of which are summarized in the World Database of Happiness, Correlational Findings (Veenhoven 2011d), section H6.1.3 'Current happiness: Overall happiness by Contentment'. The analysis was limited to studies among general population samples using comparable single direct questions on overall happiness (type O-HL, O-SL, O-DT) and contentment (type C-BW).

7 This analysis involved 70 studies, the results of which are summarized in the World database of Happiness, Correlational Findings (Veenhoven 2011d), section H6.1.2 'Current happiness: Overall happiness by Hedonic level of Affect'. The analysis was limited to studies among general population samples using comparable single direct questions on overall happiness (type O-HL, O-SL, O-DT, OQOL) and Affect Balance (type A-AB). See also Suh et al. 1998.

8 This analysis involved 3 studies, the results of which are summarized in the World Database of Happiness, Correlational Findings (Veenhoven 2011d), section H6.23 'Current happiness: Hedonic level of Affect by Contentment'. The analysis was limited to studies among general population samples. Hedonic level was measured using Affect balance Scales (type A-AB) and contentment using the Cantril ladder (type C-BW) and questions about perceived realization of wants (type C-RW).

9 World Database of Happiness, Correlational Findings, subject section 'Current Income' (1.2) For a recent cross-national comparison see Ball and Chernova (2008).

${ }^{10}$ World Database of Happiness, Correlational Findings (Veenhoven 2011d), subject section 'Current Occupational level' (01.3.1).

${ }^{11}$ World Database of Happiness, Correlational Findings (Veenhoven 2011d), subject section 'Subjective Social Rank' (S9.2.2).

12 World Database of Happiness, Correlational Findings, subject section 'Objective Social Status' (S9.2.1).

13 World Database of Happiness, Correlational Findings (Veenhoven 2011d), subject section 'Subjective Social Rank' (S9.2.2).

14 World Database of Happiness, Correlational Findings, subject section 'Objective Social Status'(S9.2.1). 
15 World Database of Happiness, Correlational Findings (Veenhoven 2011d), subject 'Marital Status' (M2.1). See also Diener, Gohm, Oishi, and Suh (2000).

16 World Database of Happiness, States of Nations (Veenhoven 2011f). variable r_LS_Education_1990.

17 World Database of Happiness, Correlational Findings (Veenhoven 2011d), subject 'Later Work Performance'(code W6.1.4).

${ }^{18}$ World Database of Happiness, Correlational Findings (Veenhoven 2011d), subject 'Later Leisure' (code L3.1.4).

${ }^{19}$ World Database of Happiness, Correlational Findings (Veenhoven 2011d), subject 'Later Friendships' (code F6.1.4).

20 World Database of Happiness, Correlational Findings (Veenhoven 2011d), subject 'Later Marriage' (code M1.4). See also Veenhoven (1989).

${ }^{21}$ World Database of Happiness, Correlational Findings (Veenhoven 2011d), subject 'Later Organizational Participation' (code S7.1.4).

22 World Database of Happiness, Correlational Findings (Veenhoven 2011d), subject 'Later Physical Health' (code P6.1.4). See also Veenhoven (2008b).

23 World Database of Happiness, Correlational Findings, subject Longevity' (code P6.1.4.1). See also Veenhoven (2008a).

24 World Database of Happiness, Bibliography of Happiness (Veenhoven 2011g), subject 'Moral Appreciation of Happiness, by the General Public' (Code Sb02.02).

${ }^{25}$ World Database of Happiness, Bibliography of Happiness (Veenhoven 2011g), subject 'Perceived Sources of Happiness' (code 15a2). For a recent review see McMahon (2008).

${ }^{26}$ World Database of Happiness, Bibliography of Happiness, subject 'Perceived Sources of One's Own Happiness' (code Sc01).

27 Overall Happiness measured with a survey question on life-satisfaction. Average contentment, as measured with Cantril's Best-Worst possible life question, is closer to neutral, which fits the prediction of comparison theory.

${ }^{28}$ World Database of Happiness, Happiness in Nations (Veenhoven 011b), Rank report average happiness. See also Diener 1996. 


\section{REFERENCES}

Ball, R., \& Chernova, K. (2008).

Absolute income, relative income and happiness.

Social Indicators Research, 8, 479-529.

Bentham, J. (1789).

Introduction to the principles of morals and legislation.

(Original London: Payne. Reprinted London: Althone Press, 1970).

Biswas-Diener, R., Diener, E., \& Vitterso, J. (2005).

Most people are pret ty happy, but there is cultural variation: The Inug huit, the Amish and the Maasai.

Journal of Happiness Studies, 6, 205-226.

Brockmann, H., Delhey, J., Welzel, C., \& Yuan, H. (2009).

The China puzzle: Falling happiness in a rising economy.

Journal of Happiness Studies, 10(A), 347-405.

Bruckner, P. (2000).

L'euphorie perpétuelle: Essai sur le devoir de bonheur.

Paris: Grasset.

Cantril, H. (1965).

The pattern of human concern.

New Brunswick, NJ: Rutgers University Press.

Chambers, J. C. (1999).

Situating psychological well-being: Exploring cultural roots of its theor $y$ and research.

Journal of Counseling and Development, 77, 141-152.

Chiasson, N., \& Dubé, L. (1997).

La conception du bonheur: Similitudes et differences interculturelles.

Revue Québécoise de Psychologie, 18, 121-144.

ChinHonFoei, S. S. (2007).

Gender equality and happiness in nations.

Paper presented at Dag van de Sociologie, Tilburg University 8-6-2006.

Cohen, S., Doyle, W. J., Skomer, D. P., Fireman, P., Gwaltney, J. M., \& Newson, J. P. (1995).

State and trait negative affect as predictors of subjective and objective symptoms of respiratory viral infections.

Journal of Personality and Social Psychology, 68, 159-169. 
Damasio, A. (1994).

Descartes' error.

New York: Putnam.

Davidson, R. J. (2004).

Well-being and affective st yle: Neural substrates and biobehavioural correlates.

Philosophical Transactions, Biological Sciences, 359, 1395-1341.

Diener, E. (1996).

Most people are happy.

Psychological Science, 7, 181-185.

Diener, E., Emmons, R. A., Larsen, R. J., \& Griffin, S. (1985).

The satisfaction with life scale.

Journal of Personality Assessment, 49, 71-75.

Diener, E., Gohm, C. L., Oishi, S., \& Suh, E. M. (2000).

Similarity of the relation between marital status and subjective well-being across cultures.

Journal of Cross-Cultural Psychology, 31, 419-436.

Diener, E., \& Oishi, S. (2004).

Are Scandinavians happier than Asians? Issues in comparing nations on subjective well-being.

Asian Economic and Political Issues, 10, 1-25.

Ekman, P. (1970).

Universal facial expression of emotion.

Californian Mental Health Research Digest, 8, 151-158.

Fredrickson, B. L. (2004).

The broaden-and-build theory of positive emotions.

Philosophical Transactions, Biological Sciences, 359, 1367-1377.

Harter, J. K., \& Arora, R. (2010).

The impact of time spent working and job-fit on well-being around the world. In E. Diener, J. F. Helliwell, \& D. Kahneman (Eds.), International differences in wellbeing (pp. 398-436).

New York: Oxford University Press.

Headey, B., \& Veenhoven, R. (1989).

Does happiness induce a rosy outlook? In R. Veenhoven (Ed.), How harmful is happiness? Consequences of enjoying life or not (pp. 106-127).

The Hague: University Press Rotterdam. 
House, R. J., H anges, P. J., Javadin, M., D orfman, P. W., \& Gupta, V. (2004). Culture, leadership and organizations. The GLOBE study of 62 societies.

London: Sage.

Inglehart, R., Foa, R., Peterson, C., \& Wetzel, C. (2008).

Development, freedom and rising happin ess: A gl obal perspective 1981-2007. Perspectives in Psychological Science, 3, 268-285.

Isen, A. M., Doubman, K. A., \& Nowiki, G. P. (1998).

Positive affect facilitates creative problem solving. In J. M. Jenk ins, K. Oatley, \& N. L. Stein (Eds.), Human emotions: A reader (pp. 288-297).

Malden, MA: Blackwell.

Kuppens, P., Realo, A., \& Diener, E. (2008).

The role of positive and negat ive emotions in life-satis faction judgment across nations.

Journal of Personality and Social Psychology, 95, 66-75.

Lee, D. Y., Park, S. H, Uhleman, M. R., \& Patsula, P. (1999).

What makes you happy? A c omparison of self-reported criteria between two cultures.

Social Indicators Research, 50, 351-362.

Lucas, R. E., Diener, E., Grob, A., Suh, E. M., \& Shao, L. (2000).

Cross-cultural evidence for the fundamental features of extraversion.

Journal of Personality and Social Psychology. 79, 452-468.

Lyubomirsky, S., Diener, E., \& King, L. A. (2005).

The benefits offrequent positive affect: Does happ iness lead to success? Psychological Bulletin, 131, 803-855.

Maslow, A. H. (1970).

Motivation and personality.

New York: Harper, \& Row.

McMahon, D. M. (2008).

The pursuit of happiness in history. In M. Eid, \& R. J. Larsen (Eds.), The science of subjective well-being (pp. 80-93).

New York: The Guilford Press.

Oishi, S., Diener, E., Lucas, R. E., \& Suh, E. (1999).

Cross-cultural variation in predictors of life-satisfaction: Perspectives from needs and values.

Personality and Social Psychology Bulletin, 25, 980-990.

Rayo, L., \& Becker, G. S. (2007).

Evolutionary efficiency and happiness.

Journal of Political Economy, 115, 302-337. 
Russell, J. A. (1994).

Is there universal recognition of emotion from facial expression? A review of crosscultural studies.

Psychological Bulletin, 115, 102-141.

Schimmack, U., Ra dharkrishan, P., Oishi, S., Dzokoto, V., \& Ahadi, S. (2002). Culture, personality and s ubjective well-being: Integrating process model of life satisfaction.

Journal of Personality and Social Psychology, 82, 582-593.

Spogárd, R. (2005).

World opinion: A happy family and good health is what matters most in life. http://www.gallupintemational.com/ContentFiles/millenium16.asp. Accessed 01-01 -2009.

Suh, M. E., Diener, E., Oishi, S., \& Triandis, H. C. (1998).

The shifting basis of life satisfaction judgments across cultures: Emotion versus norms.

Journal of Personality and Social Psychology, 74, 482-493.

Thin, N. (2008).

'Realising the substance of their happiness': How anthropology forgot about Homo Gauisus. In J. S. Corsin (Ed.), Culture and well-being (pp. 134-155).

London: Pluto Press.

Tsai, J., Knutson, B., \& Fung, H. H. (2006).

Cultural variation in affect valuation.

Journal of Personality and Social Psychology, 90, 288-3-7.

Veenhoven, R. (1984a).

Conditions of happiness.

Dordrecht, The Netherlands: Reidel (now Springer).

Veenhoven, R. (1984b).

Databook of happiness: A complementary reference work to conditions of happiness .

Dordrecht, The Netherlands: Reidel (now Springer).

Veenhoven, R. (Ed.) (1989).

How harmful is happiness? Consequences of enjoying life or not.

The Hague, The Netherlands: University Press Rotterdam.

Veenhoven, R. (1991).

Is happiness relative?

Social Indicators Research, 24, 1-34. 
Veenhoven, R. (1995).

The cross-national pattern of happiness: Test of predictions implied in three theories of happiness.

Social Indicators Research, 34, 33-68.

Veenhoven, R. (2000).

The four qualities of life: Ordering concepts and measures of the good life.

Journal of Happiness Studies, 1, 1-39.

Veenhoven, R. (2008a).

Comparability of happiness across nations.

School of Sociology and Social Work Journal, 704,211-234.

Veenhoven, R. (2008b).

Healthy happiness: Effects of happiness on physical health and the consequences for preventive health care.

Journal of Happiness Studies, 9, 449 -464.

Veenhoven, R. (2009a).

World database of happiness: Tool for dealing with the 'data-deluge'.

Psychological Topics, 18, 221-222.

Veenhoven, R. (2009b).

How do we assess how happy we are? In A. Dutt, \& B. Radcliff (Eds.),

Happiness, economics and politics: Towards a multi disciplinary approach (pp. 45-

69).

Cheltenham, UK: Edward Elgar Publishers.

Veenhoven, R. (2010).

Life is getting better: Societal evolution and fit with human nature.

Social Indicators Research, 97, 105-122.

Veenhoven, R. (2011a).

World database of happiness: Continuous register of scientific research on subjective enjoyment of life.

Rotterdam, The Netherlands: Erasmus University Rotterdam. Available at: http://worlddatabaseofhappinss.eur.nl.

Veenhoven, R. (2011b).

Happiness in nations. World Database of Happiness. Rotterdam, The Netherlands: Erasmus University Rotterdam.

Available at: http://worlddatabaseofhappiness.eur.nl/hap_nat/nat_fp.php.

Veenhoven, R. (2011c).

Happiness in publics. World Database of Happiness.

Rotterdam, The Netherlands: Erasmus University Rotterdam. Available at:

http://worlddatabaseofhappiness.eur.nl/hap_pub/pub_fp.php. 
Veenhoven, R. (2011d).

Correlates of happiness. World Database of Happiness.

Rotterdam, The Netherlands: Erasmus University Rotterdam. Available at:

http://worlddatabaseofhappiness.eur.nl/hap_cor/cor_fp.htm.

Veenhoven, R. (2011e).

Measures of happiness. World Database of Happiness.

Rotterdam, The Netherlands: Erasmus University Rotterdam. Available at:

http://worlddatabaseofhappiness.eur.nl/hap_quer/hqi_fp.htm.

Veenhoven, R. (2011f).

States of nations. World Database of Happiness.

Rotterdam, The Netherlands: Erasmus University Rotterdam. Available at:

http://www.worlddatabaseofhappiness.eur.nl/statnat/statnat_fp.htm.

Veenhoven, R. (2011g).

Bibliography of happiness. World Database of Happiness.

Rotterdam, The Netherlands: Erasmus University Rotterdam, http://worlddatabaseofhappiness.eur.nl/hap_bib/bib_fp.php.

Veenhoven, R., \& Hagerty, M. (2006).

Rising happiness in nations, 1946-2004: A reply to Easterlin.

Social Indicators Research, 79, 421-436.

Verne, P. (2008).

Happiness, freedom and control.

Journal of Economic Behavior and Organization, 71, 146-161.

Wentholt, R. (1980).

Map motivatieleer.

Rotterdam, The Netherlands: Erasmus Universiteit Rotterdam.

Wessman, A. E. (1956).

A psychological inquiry into satisfaction and happiness.

Unpublished Doctoral Dissertation, Princeton, NJ: Princeton University.

Wilson, E. G. (2008).

Against happiness: In praise of melancholy.

New York: Sarah Crichton Books/FSG.

World Values Survey. (2010).

Available at: http://www.worldvaluessurvey.org

Zajonc, R. B. (1984).

On the primacy of affect.

American Psychologist, 39, 117-123. 